\title{
Gender-Sensitive Peer Counselling Groups in Times of Conflict Reflections on a Self-Help Support Group in Berlin
}

\author{
Jinan Abi Jumaa* and Andreas Heinz \\ Charité - Universitätsmedizin Berlin, Germany
}

\begin{abstract}
The arrival of stark number of forcibly displaced refugees in Germany since 2015 has led to increased challenges in the mental health care system. The system was overburdened, and therefore innovative approaches to health care for refugees were necessary in order to gain knowledge about their expansion and admission to regular care. To increase knowledge of refugees regarding mental health services and to provide practical support, a manual for peer-to-peer counseling was developed at Charité University Medical Center Berlin and refugees were trained as peer counsellors. This paper aims to give an overview of previous peer support interventions published in literature and to also point out to the preliminary results from the intervention conducted at the Charité. Good practices and recommendations for peer interventions are provided. Qualitative interviews were conducted with the group participants, and results show that peer groups helped refugees in sharing experiences, in giving ideas for possible solutions, in building social/friendship networks, and in providing a safe place for discussions. The results of our study suggest that integrating gender-sensitive peer support approaches in the mental health services for refugees may benefit the public health by reducing both need and demand for these services.
\end{abstract}

Keywords: refugees, mental health, public health, peer support, self-help interventions, culture accessibility, self-management, stepped care collaborative model

\section{Introduction}

The world currently witnesses a stark increase of refugees who have fled their countries because of war, poverty and persecution (Trilesnik et al., 2019).

The ongoing war in the Middle East, has drastically increased the number of refugees arriving in the European Union since 2014. In 2015, the number of refugees crossing the borders into Germany reached 1.1 million (Cofrancisco, 2016). According to demographic statistics from the "Federal Office for Migration and Refugees Bundesamt für Migration und Flüchtlinge" (BAMF), the largest group of immigrants has been coming from Syria, and the second most important country of origin in 2015 was Afghanistan (ibid). In November 2015 alone, Berlin received 10,000 refugees (ibid). Refugees who had been confronted with countless harsh experiences during their flight, have to now deal with stressful challenges in Germany to meet their basic needs including integration, education, language skills, mental and physical health care (World Health Organization, 2018). The challenges that refugees faced in the host country were complicated such as lack of adequate support systems, family dislocation, distrust, unfamiliarity with the language and culture of the host society, inaccessibility of services, isolation, discrimination and racial intolerance. This can in turn induce stress and depression (Behnia, 2007). Research shows that high scores of psychiatric problems and disorders are present among refugees, and there are an increasing number of scientific studies that explicitly measure psychopathology (Laban et al., 2004).

The right of everyone to have access to physical and mental health is established in the WHO Constitution of 1948. International Human rights standards exist to protect the rights of refugees and migrants, including the right to health, however many refugees often lack access to health care services due to various reasons (World Health Organization, 2020). 
Language difficulties are particularly considered a barrier when accessing healthcare, and this hurdle in the healthcare system is not overcome by regular financing of professional interpreters (Kluge, 2020). Administrative difficulties and long process times for refugee applications' assessment also present another difficulty that decrease refugees 'motivation to deal with topics that are detached from legal issues and residence permits, e.g. mental health (Demir, 2015).

Another repeatedly cited obstacles to healthcare is a lack of knowledge about what is provided by the German healthcare system(ibid), as well as the stigma towards mental health in general (Chuah et al., 2018) and the different understandings of disease and treatment that is highly influenced by culture and country of origin; that is so-called as the explanatory models of illness (Kleinman \& Benson, 2006).

It is common for researchers and physicians to focus on the trauma that refugees have passed through; either before resettlement including political violence and war, during their routes to the host country and after their resettlement including their struggles with a new language, new social life, discrimination and integration. Therefore, any refugee will have been subject to some form of trauma in their lives either directly or indirectly (Block et al., 2018), and this explains why the majority of interventions focus on treatment of symptoms such as Post Traumatic Stress Disorder (PTSD) (ibid). Many interventions, yet, still lack the culturally sensitive, low threshold element that is proven to help refugees a great deal (Zellmann, 2017).

Previous studies show that it is of utmost significance not to label all refugees as suffering from some type of pathology because they are all individuals going through extraordinary circumstances (Block et al., 2018). Health care professionals should be conscious of cultural differences that may arise when interacting with refugees and to seek strengths-based and empowerment-based approaches for work with them (Abi Jumaa et al., 2019; Block et al., 2018).

The stark number of refugees that arrived in Germany in 2015 put the healthcare systems under pressure as they were not well-equipped or prepared to deal with such the sudden situation (Böge et al., 2019). The general lack of psychiatric care for refugees, and the particular lack of funding for language mediators, cultural sensitivity, as well as professional specialization and integration put Germany under a great challenge to meet the needs of this population (Bajbouj et al., 2018). Studies show that access restrictions are associated with higher expenditures and long-term economic disadvantage (Bozorgmehr \& Razum, 2015).

To deal with this situation, a recommendation from the WHO was adapted that stated that an increase in the utilization and coverage of mental health care interventions settings such as developing low threshold programs would have positive impacts to overcome lack of access to health care (World Health Organization, 2004).

As such the Inter-Agency Standing Committee developed a set of guidelines that aimed at protecting and improving people's mental health and psychosocial well-being in emergency settings (Inter-Agency Standing Committee (IASC), 2007).

According to Bajbouj et al. (2018), the German health system was mainly focusing on the fourth level of the pyramid (clinical intervention), that is the more specialized measures that require more formal trainings and specialist personals, however the easily available, low-threshold and generally applicable interventions from the pyramid (first, second and third level) are often not well coordinated and only implemented irregularly (Bajbouj et al., 2018).

Also, in certain circumstances such as immediately after refugees' arrival, interventions are advised not to be deficit-oriented and trauma-confrontative, but rather enable security and self-help when possible (Zellmann, 2017). 
For all of the above-mentioned reasons, a cost- effective, culturally-sensitive, peer support program was developed at the Charité. Its main principle was to empower refugees by providing them with skills to handle their stress, and self-awareness, which are necessary to guide their behaviours and to improve the quality of their lives. This program did not identify refugees as weak ties, but rather considered them and the trained group leader as equals, who discover and understand meanings of symptoms together.

The aim of this paper is to give an overview of the preceding peer-support self-help groups for refugees that were published in the literature and highlight our preliminary findings from the program that was administered at the Charité.

\section{Overview on peer support interventions}

The World Health Organization (WHO) focuses on patient-centred and integrated health services that is a fundamental paradigm shift in the way health services are funded, managed and delivered; unless a patientcentred and integrated health services approach is adopted, health care will become increasingly fragmented, inefficient and unsustainable (World Health Organisation, 2015). Strengthening patient and public involvement and involving those with lived experiences has been reported to increase their skills and training opportunities (ibid).

Integrating peers in the healthcare environment appear to be important and emerging intervention in the field of mental health and recovery services (Chinman et al., 2014).

The term 'peer' describes a person who share similarities with another group, such as similar professions, cultural background, living conditions or mental illness (Zellmann, 2017).

Theoretically embedded in the social relationship construct (See Figure 1) (Dennis, 2003b), peer support programs are considered valuable means to complement the psychosocial care systems (Webel et al., 2010), these interventions demonstrated effective results on patients wellbeing and on effectively reducing stigmatization in mental healthcare and also on reducing healthcare costs (ibid). For example, Chinman et al (2001) reveals a 50 per cent reduction rate in re-admissions to hospitals, studies by Lawn et al. (2008) demonstrated that over 300 bed days were saved over a three-month period when peer support workers were employed (Chinman et al., 2014; Lawn et al., 2008).

Unambiguously, recognizing the greater benefits of preventing illness rather than treating it, health promotion does not solely include nutrition, weight control, exercise, and stress management but also the enhancement of supportive relationships within a social network (Dennis, 2003a). Lakey and Cohen (2000) state that social support acts as a stress buffer by reducing the effects of stressful life events on health through supportive actions (receiving advice from others), or by believing that support is available, by interpreting stressful situations less negatively and by helping to create and sustain identity and self-esteem (Lakey \& Cohen, 2000). 


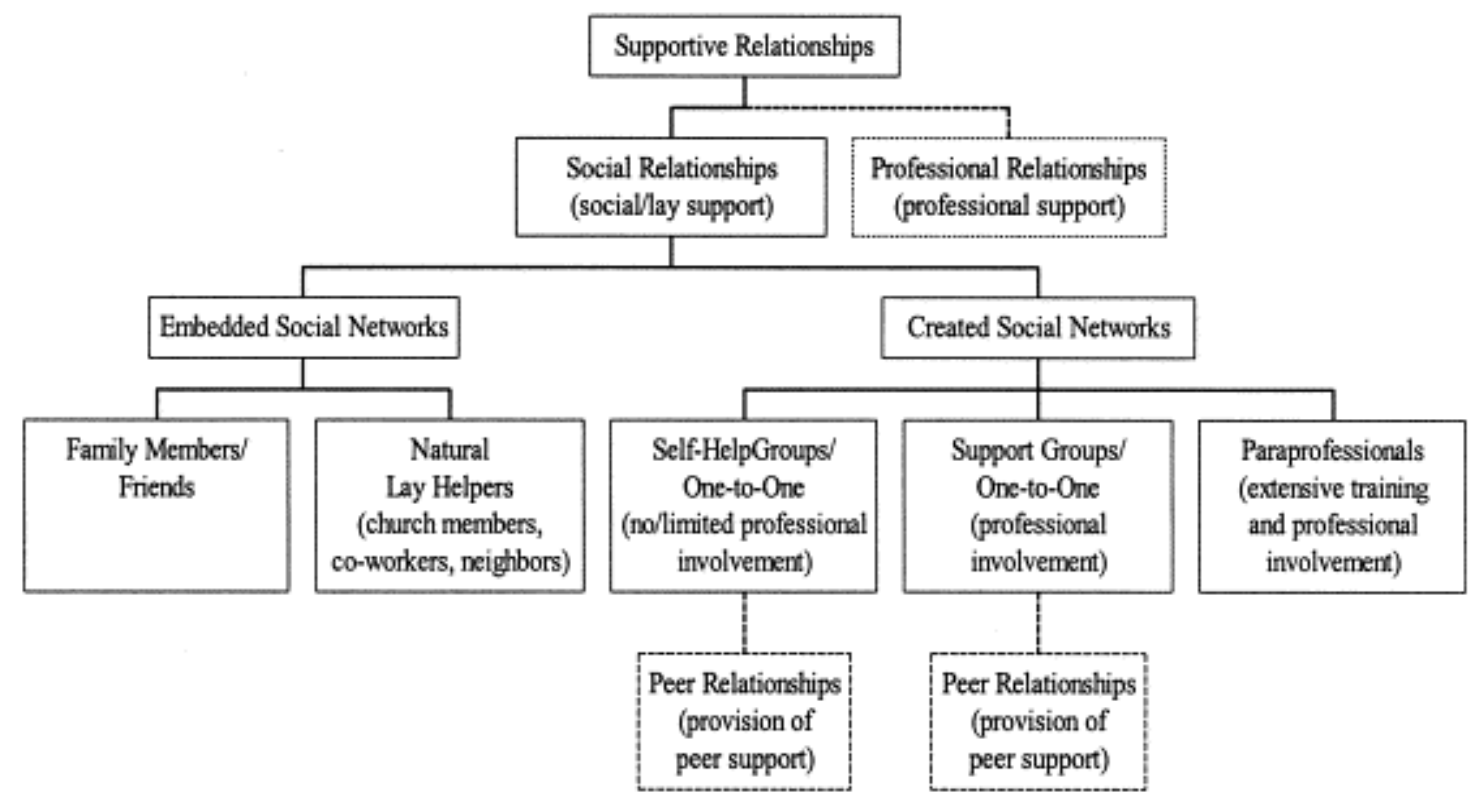

Lay

Professional

Figure 1. Social relationship classification. Retrieved from (Dennis, 2003b)

To have a better overview about the previous peer support programs that was administered to help refugees overcome their psychological issues, an overview on literature was conducted. The aim was to aggregate evidence from the interventions that describe the effects of peer support on refugees' mental health and psychosocial wellbeing. To conduct the literature review, the following Databases were used: Google Scholar, Research Gate and Humboldt University Library Database and the search key words were: Peer-to-Peer AND Refugees OR Asylum Seekers AND Mental Health AND/OR Psychosocial. Criteria for studies inclusion were: 1) Projects that tackle the effect of $\mathrm{P} 2 \mathrm{P}$ or non-traditional psychological counselling on refugees' mental health. 2) Targeted population was refugees 3) And could be both males and/or females. 4) Age was also not limited.

The projects that focused on the effects of $\mathrm{P} 2 \mathrm{P}$ on physical health and sexual health, or non-refugee population were excluded. The findings are summarized in the table below (See table 1.). Please note that the table represent a narrative review rather than a systematic meta-analysis.

Table 1: Overview of P2P programs that targeted refugees' mental health

\begin{tabular}{|c|c|c|c|c|}
\hline $\begin{array}{l}\text { First author } \\
\text { (year) }\end{array}$ & $\mathbf{N}$ & Age /Gender & Study Design & Major results \\
\hline $\begin{array}{l}\text { (Block et al., } \\
\text { 2018) }\end{array}$ & 79 & Adults/mixed & $\begin{array}{l}\text { McNemar, pre-and } \\
\text { post-assessment }\end{array}$ & $\begin{array}{l}\text { Peer support groups helped in making } \\
\text { friends and better access to their own } \\
\text { community, in becoming more } \\
\text { independent. } \\
\text { Better access to healthcare, job resources, } \\
\text { transportation and school }\end{array}$ \\
\hline (Tol et al., 2020) & 613 & Adults/female & $\begin{array}{l}\text { Randomized } \\
\text { Control Trial } \\
(\mathrm{RCT})\end{array}$ & $\begin{array}{l}\text { Self- help intervention resulted in larger } \\
\text { improvements in psychological distress, } \\
\text { PTSD and depression symptoms, } \\
\text { explosive anger, functional impairment, } \\
\text { and subjective wellbeing at } 3 \text { months } \\
\text { post intervention compared with usual } \\
\text { care. }\end{array}$ \\
\hline
\end{tabular}




\begin{tabular}{|c|c|c|c|c|}
\hline $\begin{array}{l}\text { (Abi Jumaa et } \\
\text { al., 2019) }\end{array}$ & 26 & $\begin{array}{l}18-65 \\
13 \text { females } \\
13 \text { males }\end{array}$ & $\begin{array}{l}\text { Qualitative } \\
\text { interviews }\end{array}$ & \\
\hline $\begin{array}{l}\text { (Golchert et al., } \\
\text { 2019) }\end{array}$ & 234 & $\begin{array}{l}18-65 \\
\text { Mixed }\end{array}$ & RCT & $\begin{array}{l}\text { Excepted benefits: Low-threshold app- } \\
\text { based intervention will lower } \\
\text { posttraumatic symptom severity and } \\
\text { associated secondary outcomes in favor of } \\
\text { overall improved wellbeing and quality of } \\
\text { life }\end{array}$ \\
\hline $\begin{array}{l}\text { (Flegg et al., } \\
\text { 2015) }\end{array}$ & 131 & $\begin{array}{l}\text { Adults/ } \\
\text { Mixed }\end{array}$ & $\begin{array}{l}\text { Focus group } \\
\text { Online survey } \\
\text { Public consultation } \\
\text { day }\end{array}$ & $\begin{array}{l}\text { Peer-to-peer support services was an } \\
\text { innovative approach to reducing suicide, } \\
\text { self-harm, reliance on public health } \\
\text { services (GPs, hospital stays, etc.) and } \\
\text { engaging with drugs, alcohol and criminal } \\
\text { activity. }\end{array}$ \\
\hline $\begin{array}{l}\text { (Wollersheim et } \\
\text { al., 2017) }\end{array}$ & 29 & $\begin{array}{l}\text { 35-40 years } \\
\text { old/ females }\end{array}$ & $\begin{array}{l}\text { Pre-post study } \\
\text { design (Qualitative) }\end{array}$ & $\begin{array}{l}\text { Project concluded that the value of } \\
\text { information for marginalized people is } \\
\text { important, and the usefulness of } \\
\text { technology help provide that information. }\end{array}$ \\
\hline (Wöller, 2016) & 49 & Adults/mixed & $\begin{array}{l}\text { Qualitative follow- } \\
\text { up }\end{array}$ & $\begin{array}{l}\text { Peer groups helped in the following: } \\
\text {. taking care of refugees with trauma } \\
\text { disorders } \\
\text { - activate refugees' resources } \\
\text { Moreover, study suggested that peer } \\
\text { groups should be integrated into a } \\
\text { comprehensive care system and receive } \\
\text { professional support through supervision. }\end{array}$ \\
\hline $\begin{array}{l}\text { (Wollersheim et } \\
\text { al., 2017) }\end{array}$ & 29 & Adults/mixed & $\begin{array}{l}\text { Qualitative } \\
\text { interviews }\end{array}$ & $\begin{array}{l}\text { Peer groups helped in the following: } \\
\text {. allowing women to be connected to their } \\
\text { families and the wider communities. } \\
\text {. assisting them to access health care and } \\
\text { other settlement aspects with greater ease. } \\
\text {. increasing personal empowerment } \\
\text { playing role as social support among } \\
\text { group members. }\end{array}$ \\
\hline $\begin{array}{l}\text { (Im \& } \\
\text { Rosenberg, } \\
\text { 2016) }\end{array}$ & 22 & $\begin{array}{l}\text { Adults/ } 18 \\
\text { females, } \\
4 \text { males }\end{array}$ & $\begin{array}{l}\text { Qualitative } \\
\text { interviews }\end{array}$ & $\begin{array}{l}\text { Peer groups helped in: } \\
. \text { community building and participation } \\
. \text { increasing sense of community } \\
\text {. increasing sense of belonging }\end{array}$ \\
\hline (Dennis, 2003a) & 121 & $\begin{array}{l}25-50+\text { years } \\
\text { old/ females }\end{array}$ & $\mathrm{RCT}$ & $\begin{array}{l}\text { P2P helped in: } \\
\text {. effective preventative intervention } \\
\text {. enhancing interpersonal and } \\
\text {. communication skills } \\
\text {. increasing knowledge, organizational } \\
\text { and managerial skills } \\
\text {. improving job opportunities }\end{array}$ \\
\hline $\begin{array}{l}\text { (Ayoughi et al., } \\
\text { 2012) }\end{array}$ & 61 & $\begin{array}{l}\text { 14-60 years } \\
\text { old/ females }\end{array}$ & $\begin{array}{l}\text { Pre-post } \\
\text { intervention } \\
\text { (quantitative) }\end{array}$ & $\begin{array}{l}\text { P2P helped in: } \\
\text {. high improvements with respect to the } \\
\text { severity of symptoms of depression and } \\
\text { anxiety } \\
\text {. reduction of psychosocial stressors } \\
\text {. enhancement of coping strategies }\end{array}$ \\
\hline
\end{tabular}




\begin{tabular}{|c|c|c|c|c|}
\hline $\begin{array}{l}\text { (Stewart et al., } \\
\text { 2012) }\end{array}$ & 29 & $\begin{array}{l}\text { Adults/ } 13 \\
\text { males, } \\
16 \text { females } \\
\text { Sudanese }\end{array}$ & $\begin{array}{l}\text { Qualitative } \\
\text { interviews }\end{array}$ & $\begin{array}{l}\text { Peer groups helped in } \\
\text {. connecting with people from African } \\
\text { refugee participants' cultural } \\
\text { communities. } \\
\text {. increasing social integration } \\
\text {. decreasing loneliness } \\
\text {. expanding coping repertoire. }\end{array}$ \\
\hline $\begin{array}{l}\text { (Stewart et al., } \\
\text { 2011) }\end{array}$ & 58 & $\begin{array}{l}21-60 \text { years } \\
\text { old } \\
31 \text { males, } \\
27 \text { females }\end{array}$ & $\begin{array}{l}\text { Pre-post study } \\
\text { design }\end{array}$ & $\begin{array}{l}\text { P2P helped in: } \\
\text { increasing in perceived support and } \\
\text { social integration } \\
\text {. decreasing in loneliness } \\
\text {. increasing in learning how to seek } \\
\text { services and support } \\
\text {. better coping with challenges faced by } \\
\text { refugees }\end{array}$ \\
\hline (Behnia, 2003) & 12 & $\begin{array}{l}\text { Adults/ } 3 \\
\text { males } 9 \\
\text { females }\end{array}$ & $\begin{array}{l}\text { Qualitative } \\
\text { Interviews }\end{array}$ & $\begin{array}{l}\text { P2P helped in: } \\
\text {. helping get out of isolation } \\
\text {. providing a place to talk about their } \\
\text { problems and to receive support } \\
\text {. being understood } \\
\text {. learning about their rights } \\
\text { f finding friends } \\
\text {. getting advice } \\
\text { learning about community }\end{array}$ \\
\hline
\end{tabular}

\section{Peer to Peer Intervention}

In Germany, the treatment gap in mental health care was the consequence of a multi-component barrier prohibiting initiation and continuation of treatment among individuals with mental disorders (Böge et al., 2019). Thus, there was a necessity of culturally responsive and effective interventions for refugees to achieve better health promotion. The Federal Association of Physicians (2017) demanded that when the regulatory system is overburdened, innovative approaches to health care for migrants should be used and scientifically monitored in order to gain knowledge about their expansion and admission to regular care (Zellmann, 2017).

\section{Methods}

\section{Manual development:}

The adopted intervention developed by Missmahl and coworkers (Ayoughi et al., 2012), who conducted a peerbased intervention in Mazar-e-Sharif in Afghanistan included a manual that was developled with the help of Berger and other colleagues at Charite (Berger et al., 2007).

The manual included the following topics: Session 2/Theme 1: Stress and resilience Session 3/Theme 2: Expectations vs. Realities Session 4/Theme 3: Visions and Dreams Session 5/Theme 4: Cultural shocks faced in Germany Session (See table 2.)

Each session also included breathing exercises and muscular relaxation techniques. Sessions usually took 90 minutes (with optional 5-10min break), occurred once or twice per week per week, and included 10-15 participants per group with 1-2 refugee group leaders. 
Table 2. Description of the peer support groups'session

\begin{tabular}{ll}
\hline Session 1 & Orientation to Group and 'Stress and Resilience' \\
& Establishing the group rules \\
& 'Who is who' exercise \\
& Discussion and exercise on Stress \\
& Progressive Muscle Relaxation and Breathing Exercise \\
\hline Session 2 & 'Reality vs. Expectations' \\
& Is Germany as you expected \\
& What do you tell your families in your home countries about Germany? \\
& Progressive Muscle Relaxation and Breathing Exercise \\
\hline Session 3 & 'Visions and Dreams' \\
& Understanding your values \\
& Pictures representing values \\
& Progressive Muscle Relaxation and Breathing Exercise Progressive Muscle Relaxation and \\
& Breathing Exercise \\
\hline Session 4 & 'Cultural differences and misunderstandings' \\
& What customs are important for you to keep, and what ones are not as important to you? \\
& Are the German customs that you admire? \\
& Muscle Relaxation and Breathing Exercise
\end{tabular}

\section{Recruitment}

A multi-strategic approach to recruit Arabic and Farsi speaking refugees living in Berlin was conducted. This included using established contacts with facilities frequently used by refugees (e.g. refugee cafes, psychosocial centres, information centres, language schools, hospitals, clinics, primary care practices, psychotherapeutic practices, etc.). Social media (Facebook) was used to spread information about the study. Flyers were also displayed in differed areas in appropriate public spots across Berlin. In the pilot study, 17 participants were included ( 9 males and 8 females). Inclusion criteria included Arabic or Farsi speaking refugees living in Berlin, Germany, aged 18-65 years Exclusion criteria included Severe depressive symptomatology (Patient Health Questionnaire/PHQ-9 $\geq 20$ ) or severe suicidal thoughts. They were from Syria and Afghanistan. A total of 3 trainings were performed, each with 4 sessions. It was conducted by two psychotherapists at Charite Medical University in English and then translated into Arabic by the author. The trainings were not recorded, but notes, protocols and observation were taken after each session. After the training, a total of 10 informal semistructured interviews were conducted with those who completed the full 4 sessions. Interviews were carried out in Arabic, then translated to English by the author.

\section{Data Analysis}

Interviews were conducted in Farsi and Arabic and translated back to English by the authors. After transcription and translation, interviews were added and coded in MAXQDA software. Thematic analysis was used to analyze the data (Hsieh \& Shannon, 2005). Qualitative data were derived from the interviews and were analyzed to evaluate the satisfaction with the peer groups, the perceived benefits of such group's factors, and the preferences and the recommended changes. Two level coding were conducted where the first level was descriptive and close to the text. In the second level, categories were generated based on the recurring themes and the structured questionnaire. 


\section{Results}

Based on the data obtained from the interviews, the following preliminary results were generated:

\section{1- Benefits of peer support groups:}

Interviewees mentioned several benefits of the peer groups. Even one of them continued participating in the training even though his training sessions 'were over based on the manual. Building a safe place to share experiences and trust between the group members helped them initiating relationships and friendship and provided them with some skills to accept and listen to each other. On the one hand, exchanging experiences offered them ideas for possible solutions because they learnt from each other. And on the other hand, the person who is sharing the experiences will feel good by assisting others in finding solutions to their problems.

Even, in one case, peer groups are perceived more beneficial than individual psychotherapy by a participant as it helped him to sleep and to study better without any medication, which what often happens in the clinics. In fact, interviewees shared common concerns about drug-based treatments in usual mental health care. Also, peer groups buffered the delays in accessing healthcare.

\begin{tabular}{|c|c|}
\hline \multirow{5}{*}{ 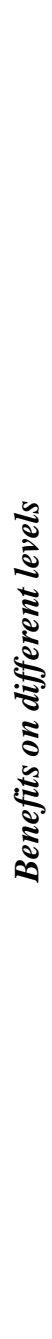 } & $\begin{array}{l}\text { Sharing experiences and giving ideas for possible solutions } \\
\text { - "It is very beneficial when I share with other women and get their feedback (I2)", } \\
\text { - "I felt the training was calm and easy. It was so comfortable during the sessions. And I was } \\
\text { waiting each week to see what we will talk about in the next session. It is sad to me that our } \\
\text { meetings have come to an end"(I3) }\end{array}$ \\
\hline & $\begin{array}{l}\text { Feeling of being productive and helpful } \\
\text { - "The sessions benefited me and the others. We share our problems. It might be the case that } \\
\text { my thought/ idea and not the peer's help someone to feel better. It is good for everything } \\
\text { (MM2)" }\end{array}$ \\
\hline & $\begin{array}{l}\text { Helping to build relations/ friendships and skills to accept others } \\
\text { - "The training was beneficial, it taught me the basics of interacting with people and helped me } \\
\text { - } \quad \text { "It helped me in very different ways. I found some friends (II)" }\end{array}$ \\
\hline & $\begin{array}{l}\text { Benefiting on the personal/ practical level } \\
\text { - "I really benefited from the training. It guided me to think better in my work and life in } \\
\text { - } \quad \text { "I learnt planning and organising my time, sleeping techniques. When we share something I } \\
\text { learn solutions from the others (I3)" }\end{array}$ \\
\hline & $\begin{array}{l}\text { Providing a safe place for sharing and discussing } \\
\text { - "Of course the training was beneficial, this is because people speak with respect to each } \\
\text { other, they share their emotions in a safe and trustful environment (I7)" } \\
\text {-I always felt more relaxed when I came to the training. You know, we as refugees have no one } \\
\text { to talk openly to. And even if we had, it is hard to trust anyone nowadays. But here I was sure } \\
\text { that what we talk about inside the room stays inside the room. I really liked that" (I9) }\end{array}$ \\
\hline
\end{tabular}


Though, most of the interviewees preferred the content of the sessions to be more flexible and personalized. These sessions for the participants are a place to share their experiences and stories, they would like to talk about their everyday struggles and experiences rather than general fixed (perceived unimportant) topics. For example, a woman participant wanted to talk more about women related topics and her challenges with her husband. Another interviewee expressed his loss of interest when the topics are continuously repeated, such as stress and depression. Some also favoured some activities to be included within the sessions such as sewing, sports, cooking etc...

\section{Group members configuration}

Gender homogeneity was mainly asked by female participants. As explained by them, this is related to the cultural practices back home in Iran, Afghanistan and the Middle East; males and females are usually separated and sometimes not allowed to be together in public events and gatherings. The rigid segregation between the sexes and the restriction of women in public spheres is socially and culturally manifested.

However, some interviewees (males and females) mentioned that they do not mind the groups to be mixed when the topics discussed are general and not private. Also, bigger groups 'size facilitates gender heterogeneity but the number of women and men in the group should be balanced to prevent domination of any group.

On the other hand, age range is favored to be homogeneous. All interviewees want the group members to be from the same age and mindset as them. Different ages might bring conflicting perspectives and uncommon problems.

The size of the group plays a role on the participants 'feeling of security. When the group is small, it is easier to notice when someone is absent, which has a negative effect on the group dynamics. That is why the participants prefer bigger groups where the fluctuation is not very visible.

In addition to that, it was repeatedly stated by the interviewees that extremely sad/depressed people in the group, increases their sadness and lowers their mood. Since they are searching for a safe and happy place, they would prefer to avoid encountering severe sadness in the session.

\begin{tabular}{|c|c|}
\hline & $\begin{array}{c}\text { Gender Homogeneity is more requested by women } \\
\text { - I cannot talk in front of men at all. It doesn't matter if they are Iranians or Afghan. I } \\
\text { just cannot (I3)." }\end{array}$ \\
- "Males and females should be split, you know I come from Iran and there, we feel more \\
comfortable to talk about topics when we are in a group from the same gender (I2)."
\end{tabular}




\begin{tabular}{|c|c|}
\hline Instability in group members bothers the participants \\
"I would prefer the trainings to have more participants because when we are more we \\
can share more, and we are more confident. I remember I was once in a group with \\
only 2 participants and no one would dare to speak anything (II)" \\
"What I didn't like was that group size was fluctuating and not stable (I4)"
\end{tabular}

\section{Conclusion}

Refugees are often labelled to suffer from PTSD and trauma-related problems which is tabulated with psychiatric labels and rarely give refugees the opportunity to express their needs or play a role in their mental health services.

Current services rarely provide the opportunity for refugees to identify their exact needs from mental health services, and this might create a hierarchal mistrustful relationship between the therapist and the refugee. Therefore, peer support programs offer a promising innovative solution for refugees' voices to be heard. They also offer a promising solution for helping to overcome language barriers and ease the access to healthcare. Additionally, because refugees are less likely to use traditional mental health services because of stigmatization and taboos, the peer-based support model provides a much-needed outlet for social and emotional healing. In addition, our results show that peer support groups can offer alternative vehicles to meet cultural preferences, they can reduce pressure on the healthcare system, enable supportive friendships and reduce the perceived stigma associated with mental health issues.

What can be suggested from our study is the development of flexible programs that can accommodate the various real time needs of refugees and should be adjusted according to the groups 'size, age and gender. Peersupport programs are best designed with offered activities such as cooking, sewing, reading or arts. And parallel activities for children are also worthwhile for mothers.

More research is needed to develop and evaluate primary preventative and innovative health care strategies for promoting mental health and preventing mental illness that respond to the increasing diversity of immigrants and refugees in Germany.

\section{Good practices in peer counselling groups:}

One of the aims of this paper was to provide with some recommendations and good practices while developing peer support groups, and it is as follows:

- Establishing trust relationships between the participants should be given special attention, as it is an integral part of the success of the group.

- The assurance of confidentiality in the groups is essential. 
- Peer group leader and participants are regarded as equals in a symmetrical relationship.

- Groups should be employed for open topics that participants would like to discuss.

- Central topics for the group sessions should nevertheless be named.

- Sensitized language and cultural groups are preferred by the participants.

- Groups must show continuity, despite possible absences of refugees.

- Moderation by a trained peer is required, as some traumatic experiences could be discussed.

- Groups should not focus on teaching specific techniques but should rather be regarded as open spaces for learning from experiences.

- Groups are preferred to be gender sensitive.

\section{Bibliography}

Abi Jumaa, J., Kluge, U., Weigold, S., Heinz, E., \& Mehran, N. (2019). Peer-to-Peer-Selbsthilfe-Interventionen für Geflüchtete-eine Pilotstudie Peer-to-Peer Self-help Interventions for Refugees: A Pilot Study. Fortschritte Der Neurologie Psychiatrie, 88(02), 89-94. https://doi.org/10.1055/a-1011-4232

Ayoughi, S., Missmahl, I., Weierstall, R., \& Elbert, T. (2012). Provision of mental health services in resourcepoor settings: A randomised trial comparing counselling with routine medical treatment in North Afghanistan (Mazar-e-Sharif). BMC Psychiatry, 12(1), 14. https://doi.org/10.1186/1471-244X-12-14

Bajbouj, M., Alabdullah, J., Ahmad, S., Schidem, S., Zellmann, H., Schneider, F., \& Heuser, I. (2018). Psychosocial care of refugees in Germany: Insights from the emergency relief and development aid. In Nervenarzt (Vol. 89, Issue 1). Springer Verlag. https://doi.org/10.1007/s00115-017-0326-y

Behnia, B. (2003). Refugees' convoy of social support: Community peer groups and mental health services. International Journal of Mental Health, 32(4), 6-19. https://doi.org/10.1080/00207411.2003.11449595

Behnia, B. (2007). An exploratory study of befriending programs with refugees: The perspective of volunteer organizations. Journal of Immigrant and Refugee Studies, 5(3), 1-19. https://doi.org/10.1300/J500v05n03_01

Berger, R., Pat-Horenczyk, R., \& Gelkopf, M. (2007). School-based intervention for prevention and treatment of elementary-students' terror-related distress in Israel: A quasi-randomized controlled trial. Journal of Traumatic Stress, 20(4), 541-551. https://doi.org/10.1002/jts.20225

Block, A. M., Aizenman, L., Saad, A., Harrison, S., Sloan, A., Vecchio, S., \& Wilson, V. (2018). Peer Support Groups: Evaluating a Culturally Grounded, Strengths-Based Approach for Work With Refugees. Advances in Social Work, 18(3), 930-948. https://doi.org/10.18060/21634

Böge, K., Karnouk, C., Hahn, E., Schneider, F., Habel, U., Banaschewski, T., Meyer-Lindenberg, A., Salize, H. J., Kamp-Becker, I., Padberg, F., Hasan, A., Falkai, P., Rapp, M. A., Plener, P. L., Stamm, T., Elnahrawy, N., Lieb, K., Heinz, A., \& Bajbouj, M. (2019). Mental health in refugees and asylum seekers (MEHIRA): study design and methodology of a prospective multicentre randomized controlled trail investigating the effects of a stepped and collaborative care model. European Archives of Psychiatry and Clinical Neuroscience, 270(1), 95106. https://doi.org/10.1007/s00406-019-00991-5

Bozorgmehr, K., \& Razum, O. (2015). Effect of restricting access to health care on health expenditures among asylum-seekers and refugees: A quasi-experimental study in Germany, 1994-2013. PLoS ONE, 10(7). https://doi.org/10.1371/journal.pone.0131483

Chinman, M., George, P., Dougherty, R. H., Daniels, A. S., Ghose, S. S., Swift, A., \& Delphin-Rittmon, M. E. (2014). Peer Support Services for Individuals With Serious Mental Illnesses: Assessing the Evidence. Psychiatric Services, 65(4), 429-441. https://doi.org/10.1176/appi.ps.201300244

Chuah, F. L. H., Tan, S. T., Yeo, J., \& Legido-Quigley, H. (2018). The health needs and access barriers among refugees and asylum-seekers in Malaysia: A qualitative study. International Journal for Equity in Health, 17(1), 120. https://doi.org/10.1186/s12939-018-0833-X

Cofrancisco, K. (2016). Cities and refugees: The German experience. https://www.brookings.edu/research/cities-and-refugees-the-german-experience/

Demir, S. (2015). Beratung nach Flucht und Migration. Ein Handbuch zur psychologischen Erstbetreuung von Geflüchteten (R. Mewes \& H. Reich (Eds.)). WeltTrends. 
Dennis, C. L. (2003a). Peer support within a health care context: A concept analysis. International Journal of Nursing Studies. https://doi.org/10.1016/S0020-7489(02)00092-5

Dennis, C. L. (2003b). Peer support within a health care context: A concept analysis. International Journal of Nursing Studies, 40(3), 321-332. https://doi.org/10.1016/S0020-7489(02)00092-5

Flegg, M., Gordon-Walker, M., \& Maguire, S. (2015). Peer-to-peer mental health: a community evaluation case study. Journal of Mental Health Training, Education and Practice, 10(5), 282-293. https://doi.org/10.1108/JMHTEP-04-2015-0019

Golchert, J., Roehr, S., Berg, F., Grochtdreis, T., Hoffmann, R., Jung, F., Nagl, M., Plexnies, A., Renner, A., König, H. H., Kersting, A., \& Riedel-Heller, S. G. (2019). HELP@ APP: Development and evaluation of a selfhelp app for traumatized Syrian refugees in Germany- A study protocol of a randomized controlled trial. BMC Psychiatry, 19(1), 1-12. https://doi.org/10.1186/s12888-019-2110-y

Hsieh, H. F., \& Shannon, S. E. (2005). Three approaches to qualitative content analysis. Qualitative Health Research, 15(9), 1277-1288. https://doi.org/10.1177/1049732305276687

Im, H., \& Rosenberg, R. (2016). Building Social Capital Through a Peer-Led Community Health Workshop: A Pilot with the Bhutanese Refugee Community. Journal of Community Health, 41(3), 509-517. https://doi.org/10.1007/s10900-015-0124-z

Inter-Agency Standing Committee (IASC). (2007). Iasc Guidelines on Mental Health and Psychosocial support in Emergency settings. http://www.humanitarianinfo.org/iasc/content/products

Kleinman, A., \& Benson, P. (2006). Anthropology in the Clinic: The Problem of Cultural Competency and How to Fix It. PLoS Medicine, 3(10), e294. https://doi.org/10.1371/journal.pmed.0030294

Kluge, U. (2020). Mental Health in Times of Increasing Flight and Migration - A German Perspective. In Health in Diversity - Diversity in Health (pp. 13-23). Springer Fachmedien Wiesbaden. https://doi.org/10.1007/978-3658-29177-8_2

Laban, C. J., Gernaat, H. B. P. E., Komproe, I. H., Schreuders, B. A., \& De Jong, J. T. V. M. (2004). Impact of a Long Asylum Procedure on the Prevalence of Psychiatric Disorders in Iraqi Asylum Seekers in The Netherlands. https://doi.org/10.1097/01.nmd.0000146739.26187.15

Lakey, B., \& Cohen, S. (2000). Social Support Theory and Measurement. https://doi.org/10.1093/med:psych/9780195126709.003.0002

Lawn, S., Smith, A., \& Hunter, K. (2008). Mental health peer support for hospital avoidance and early discharge: An Australian example of consumer driven and operated service. Journal of Mental Health, 17(5), 498-508. https://doi.org/10.1080/09638230701530242

Stewart, M., Simich, L., Beiser, M., Makumbe, K., Makwarimba, E., \& Shizha, E. (2011). Impacts of a social support intervention for Somali and Sudanese refugees in Canada. Ethnicity and Inequalities in Health and Social Care, 4(4), 186-199. https://doi.org/10.1108/17570981111250840

Stewart, M., Simich, L., Shizha, E., Makumbe, K., \& Makwarimba, E. (2012). Supporting African refugees in Canada: Insights from a support intervention. Health and Social Care in the Community, 20(5), 516-527. https://doi.org/10.1111/j.1365-2524.2012.01069.x

Tol, W. A., Leku, M. R., Lakin, D. P., Carswell, K., Augustinavicius, J., Adaku, A., Au, T. M., Brown, F. L., Bryant, R. A., Garcia-Moreno, C., Musci, R. J., Ventevogel, P., White, R. G., \& van Ommeren, M. (2020). Guided self-help to reduce psychological distress in South Sudanese female refugees in Uganda: a cluster randomised trial. The Lancet Global Health, 8(2), e254-e263. https://doi.org/10.1016/S2214-109X(19)30504-2

Trilesnik, B., Altunoz, U., Wesolowski, J., Eckhoff, L., Ozkan, I., Loos, K., Penteker, G., \& Graef-Calliess, I. T. (2019). Implementing a Need-Adapted Stepped-Care Model for Mental Health of Refugees: Preliminary Data of the State-Funded Project "RefuKey." Frontiers in Psychiatry, 10 (SEP), 688. https://doi.org/10.3389/fpsyt.2019.00688

Webel, A. R., Okonsky, J., Trompeta, J., \& Holzerner, W. L. (2010). A systematic review of the effectiveness of peer-based interventions on health-related behaviors in adults. American Journal of Public Health, 100(2), 247253. https://doi.org/10.2105/AJPH.2008.149419 
Wöller, W. (2016). Trauma-informierte Peer-Beratung in der Versorgung von Flüchtlingen mit Traumafolgestörungen. PPmP Psychotherapie Psychosomatik Medizinische Psychologie, 66(9-10), 349-355. https://doi.org/10.1055/s-0042-114992

Wollersheim, D., Koh, L., Walker, R., \& Liamputtong, P. (2017). (PDF) Happy, just talking, talking, talking: Community strengthening through mobile phone based peer support among refugee women in Melbourne, Australia. The Journal of Community Informatics. https://www.researchgate.net/publication/316452114_Happy_just_talking_talking_talking_Community_strengt hening_through_mobile_phone_based_peer_support_among_refugee_women_in_Melbourne_Australia

World Health Organisation. (2015). WHO global strategy on people-centred and integrated health services Interim Report. https://apps.who.int/iris/bitstream/handle/10665/155002/WHO_HIS_SDS_2015.6_eng.pdf?sequence=1

World Health Organization. (2004). Prevention of Mental Disorders. https://apps.who.int/iris/bitstream/handle/10665/43027/924159215X_eng.pdf?sequence=1\&isAllowed=y

World Health Organization. (2018). Mental health promotion and mental health care in refugees and migrants. http://www.euro.who.int/_data/assets/pdf_file/0004/386563/mental-health-eng.pdf?ua=1

World Health Organization. (2020). Refugee and migrant health. WHO; World Health Organization. https://www.who.int/migrants/en/

Zellmann, H. (2017). Low-threshold psychosocial support for refugees and asylum seekers - a project guide. https://www.gewaltschutz-gu.de/e5119/e5660/final-version-project-guide-msf-germany.pdf 